\title{
Globalization on the Romanian insurance market in terms of competition
}

\author{
Aurora Elena DINA (MANOLACHE) \\ The Bucharest University of Economic Studies, Bucharest, Romania \\ aurora_dina86@yahoo.com
}

\begin{abstract}
This article proposes an analysis of the globalization process impact on the Romanian insurance industry in the last decade, after accession of Romania to the European Union, in terms of competition. One of the main lines of change caused by globalization includes changes in the legislative framework, which are considered to be forced by globalization. The introduction of Solvency II directive to the beginning of 2016 year to ensure for all European insurers, the integration, globalization and the unitary functioning on the same insurance market and the recent measures taken by several Romanian insurance undertakings to strengthen their financial position could be consider a major step to further encourage the improvement of market competition and better policyholder protection. In the last ten years, the Romanian insurance sector has been faced with changes such as mergers \& acquisitions and bankruptcies that have modified the local landscape of the industry, so the majority of active companies in the market are now owned by the biggest financial groups worldwide. The results of the research reveal that the Romanian insurance market is characterised by a high concentration and competition level and in spite of the present risks, it is still attractive for foreign investors.
\end{abstract}

Keywords: insurance, market concentration, competition, globalization, Solvency II.

\section{Introduction}

Over the last ten years, like in other European insurance markets, in the Romanian insurance industry have been significant changes. The European Union accession in the 2007 year led to the internationalization of the insurance activity, increase of competition and substantially modifications in supervisory and legal frameworks. The introduction of the new solvency regulation regime Solvency II starting with January 1st 2016, had stimulated the consolidation of the insurance companies activities.

This paper focuses on an analysis of the Romanian insurance market from a structural perspective of competition and concentration level. The period examined is extended over ten years, from 2007 (the year when Romania became European Union member) to 2016 (the year when Solvency II was adopted and implemented).

This article has the following structure: a short literature review is presented in the second section of the paper, a third section containing sources of data used in the research and the methodology of the competition developed by Mereuţă, a fourth section presenting a brief description of the competition in Romania insurance market and the results of the analysis by applying the Mereuță methodology and the fifth section containing the conclusions.

\section{Literature review}

The importance of globalization in terms of the competition has been proven in numerous studies. 
Badea and Novac (2008) noted that after Romania's accession to the European Union, as a replay to the European insurance companies that penetrated on the market, the concentration of the insurance sector began to decrease itself. They suggested that the trend of insurance industry concentration from Central and Eastern European countries, as a result of the globalization process, could influence the Romanian market which may be controlled by a low number of insurance companies.

PICBE $\mid 312$

Plunkett (2006) concluded that the globalization process of (re)insurance, combined with an increasing competition on the insurance market has induced a growing expansion of insurance companies.

Pope and Ma (2008) revealed that the non-life insurance companies profitability is influenced by the degree of liberalization and concentration on the market. For the high liberalized market, the participation of the foreign insurance companies changed meaningfully the non-life-insurance dynamics. Njegomira and Marović (2012) based on the analysis of the foreign insurers participation in the countries of former Yugoslavia over the 2006 - 2009 period shown that the insurance globalization gives many advantages for the emerging countries markets like: the inflow of fresh capital, the best practices application and new types of insurance.

Previous studies of the literature concentrated on the Romanian insurance market competition analysis provided similar results.

For instance, Căpraru and Moise (2015), applying the Mereuţă methodology based on the insurers market shares from 2007-2012 period, concluded that the Romanian insurance market presents a high degree in terms of competition and present opportunities for new insurers competitors. In their view, the increase of the insurance market competition leads to a lot of problems in the relationship with the customers, especially due to the late payment or non - payment of compensation. The Mereuta methodology was also applied in the research of Mereuță and Căpraru (2012) on the Romanian banking market over the 2000 - 2010 period. Similar to the Romanian insurance market, the empirical results for the Romanian banking market derived by Mereuţă methodology shown a high competition and a low concentration.

For exemple, the study of Buşu (2012) based on insurers market shares data from year 2011 shown that the insurance sector from Romania is characterized by a high degree of competition which is correlated with a low degree of concentration. The view of Buşu pointed that a high level of concentration should not be considered only as a difficulty. For exemple in the insurance industries characterized by opportunities for specialization and high fixed costs, the increase in the size of the companies may lead to lower average costs.

\section{Methodology \\ Sources of data}

This research uses a dataset containing information about the Romanian insurance companies, based on the annual reports published by the Insurance Supervisory Commission (CSA) over a six-year period, from 2007 to 2012 and the annual reports published by the Financial Supervision Authority (ASF) over a four-year period from 2013 to 2016 available on the portal (www.asf.ro). Starting with the year 2014, on the Financial Supervision Authority web site, the data for the total gross premiums used in the market 
shares calculation was available only for the largest ten insurance companies. The data for the rest of the companies was collected from companies' annual reports and balance sheets available on their websites.

\section{Definitions}

In literature and practice, the most known indicators used in the analysis related to the competition, concentration or foreign participation on a particular market of the economy are the following:

Market Concentration Ratio (CR) is an useful indicator to determine the market share percentage of the largest companies.

Usually the number of the largest companies taken into account is between three and ten. A low concentration level suggests a high competition, while a high concentration level shows a monopolistic or oligopolistic competition (for example: a concentration ratio of 100 per cent indicates full market control by the largest undertakings). "Insurance supervisory authorities may find the ratio useful as an indicator of potential pricing control by a small number of large insurance companies. Results from market concentration analysis can be used to check, albeit crudely, if there is a possibility of oligopolistic competition in the insurance market, when a 3-firm ratio is extremely high" [Kwon and Wolfrom, 2016, p.8].

Herfindahl Index is defined as an indicator which presents the level of concentration (involving the competition) between the companies that carry out business on the same market, based on the relationship between the companies number and their market share. The Herfindahl Index is determined by summing the square market shares of all companies on the market. The interpretation of the HHI Index according to the European Commission is the following: a level less than 1000 indicates a low concentration degree, a level between 1000 and 2000 signifies a moderate competitive market and a level greater than 2000 shows monopoly market.

The Market Share of Foreign-Owned Companies represents the share of written premiums by foreign companies that carry out activities on the local market in total gross written premiums. This indicator is used to measure the speed of market liberalization in the newly open market to foreign companies and to investigate if a market is still attractive for foreign companies.

\section{Description of the methodologies applied}

This article presents a quantitative evaluation of the Romanian insurance sector competition in terms of concentration in the 2007-2016 period by applying the methodology developed by Mereuță and Căpraru (2012).

This methodology was applied in three steps: firstly, it was checked whether all the assumptions of the structural market shares distributions over the 2007-2016 period according to Mereuță's methodology are present in the Romanian insurance market; secondly, based on the M and Gdl indices from Mereuţă universal concentration matrix, it was analyzed the competition on the Romanian insurance sector and thirdly, it was conducted an analysis of the companies covering $80 \%$ of the Romanian insurance market share ("nodal" insurers analysis). 


\section{Mereuţă methodology}

The hypothesis of the market shares distribution in terms of competition developed by Mereuţă and Căpraru (2012) should be applied after checking the following characteristics:

(1) Number of the companies on the market is greater than 30;

(2) Positive asymmetry (skewed to the left) of the market distributions:

Let, $\mu$ - mean, $\sigma$ - standard deviation and $v$ the median. The positive skew is defined by the following relationship: $\mu>v$

(3) The Herfindahl indices are greater than twice the minimum value in conformity with the uniform distribution;

Let, $\mathrm{n}$ - number of companies on the market, $\mathrm{p}_{\mathrm{i}}$ - market share of companies i. Herfindahl Index is defined by the following formula:

$$
\mathrm{HHI}=\sum_{\mathrm{i}=1}^{\mathrm{n}} \mathrm{p}_{\mathrm{i}}{ }^{2} \geq \frac{2 \mathrm{n}-1}{\mathrm{n}^{2}} \quad \rightarrow \quad \mathrm{HHI} \geq \frac{2}{\mathrm{n}}, \text { for } \mathrm{n}>30
$$

(4) The markets shares smaller than average are concentrated in a single standard deviation interval because the value of the variation coefficient is greater than 1 ;

The variation coefficient is defined by the following formula:

$$
V=\frac{\sigma}{\mu} \quad \rightarrow \quad V=\sqrt{n} \times \sqrt{\frac{n \times \sum p_{i}{ }^{2}-1}{n-1}} \geq 1
$$

Let, K" - interval of the market shares smaller than average. The K" interval is defined by the following formula:

$$
K^{\prime \prime}=\frac{1-n \cdot p_{\min }}{V}, \mathrm{~V} \geq 1 \rightarrow \mathrm{K}^{\prime \prime}<1
$$

(5) Herfindahl Index of the companies covering $80 \%$ of total market share must be greater than $95 \%$ of the total Herfindahl Index;

The Normalized Herfindhal Index is defined by the following formula:

$$
H H I_{n}=\frac{H H I-\frac{1}{n}}{1-\frac{1}{n}}
$$

Mereuță and Căpraru (2012) had proposed a new concentration ratio called M, calculated by the natural logarithm of each term of the Normalized Herfindahl Index formula:

$$
M=\frac{\ln (H H I)+\ln (n)}{\ln (n)}, \mathrm{M} \in[0 ; 1]
$$

The $\mathrm{M}$ indicator has been included in five classes of concentration: (1) Class $\mathrm{A}^{+}$with very reduced concentration for values smaller than 0.2 ; (2) Class A with a reduced concentration for values between 0.2 and 0.4 ; (3) Class B with an average concentration for values between 0.4 and 0.6 ; (4) Class $C$ with high concentration for values between 0.6 and 0.8 ; (5) Class $C^{-}$with a very high concentration for values between 0.8 and 1.

Mereuță and Căpraru (2012) had also proposed another indicator, called Gdl, structural dominance of the leader defined by the formula: 


$$
G d l=\frac{\frac{p_{1}{ }^{2}}{H H I}-\frac{p_{\min }{ }^{2}}{H H I_{\min }}}{\frac{p_{\max }{ }^{2}}{H H I_{\max }}-\frac{p_{\min }{ }^{2}}{H H I_{\min }}}=\frac{\frac{p_{1}{ }^{2}}{H H I}-\frac{1}{n}}{1-\frac{1}{n}}, \quad G d l \in[0 ; 1]
$$

The Gdl indicator has also been included in five classes of concentration: (1) Class A+ with very reduced concentration for values smaller than 0.2;(2) Class A with a reduced concentration for values between 0.2 and 0.4 , (3) Class B with an average concentration for values between 0.4 and 0.6 ; (4) Class $C$ with high concentration for values between 0.6 and 0.8 ; (5) Class C- with a very high concentration for values between 0.8 and 1.

The two indicators, M and Gdl, had been included into a universal concentration matrix of non-grouped market shares composed of five areas, by applying a symmetrical scale in the range $0-1$. The significance of the five areas of universal concentration matrix is the following: (1)Zone 1- very low distortion of competition for M and Gdl coefficients with very low and low values; (2)Zone 2 - large distortion of competition for M coefficient with low and very low values and Gdl with high and very high values; Zone 3 - huge distortion of competition for $\mathrm{M}$ and Gdl coefficients with high and very high values; Zone 4 - large distortion of competition for the $\mathrm{M}$ coefficient with high and very high values and Gdl with low and very low values; Zone 5 - average distortion of competition for $\mathrm{M}$ and Gdl coefficients with averages values; Zone $5 \mathrm{a}$ - low distortion of competition for the $\mathrm{M}$ coefficient with averages values and Gdl with low and very low values; Zone $5 \mathrm{~b}$ - large distortion of competition for the $\mathrm{M}$ coefficient with large and very large values and Gdl coefficient with averages values; Zone $5 \mathrm{c}$ - large distortion of competition for the $\mathrm{M}$ coefficient with average values and Gdl coefficient with high and very high values; Zone $5 \mathrm{~d}$ low distortion of competition for the $\mathrm{M}$ coefficient with reduced and very low values and Gdl coefficient with average values.

"In terms of market accessibility, the significance of matrix zones is as follows: Zone 1 corresponds to quasi-perfect competition, with minimal entry barriers and reduced influence of the leader, establishing a clear opportunity for new competitors; Zone 3 corresponds to a competition with high entry barriers and high influence of the leader, not an opportunity for new competitors; Zones 2, 4, 5a, 5b, 5c, 5d are zones of opportunities and risks; Zone 5 corresponds to a competition with average entry barriers" [Căpraru and Moise, 2015, p.5].

\section{Results and discussions}

Starting with the accession of Romania to the European on January 1st, 2007, the foreign insurance investors could enter easier on the Romanian market. During the year 2007, a total number of 168 foreign insurers notified their intention to operate in Romania.

The increase of the competitors 'number influenced the competitive environment. After the end state monopoly of ADAS in 1990, the Romanian insurance market recorded a constant growth especially since the 2000 year, when was adopted the law regarding the insurance market supervision called Law 32/2000. In 2000 year, 73 insurers have recorded a gross volume of written premiums of 673.88 million RON, in 2007 year, 42 insurance companies have underwritten premiums in amount of 7.17 billion RON and at the end of 2016 year, the total gross written premiums by 38 insurers has reached of 9.38 billion RON. The main player in the Romanian insurance market for the ten past years is Vienna DOI: 10.2478/picbe-2018-0028, pp. 311-323, ISSN 2558-9652| Proceedings of the $12^{\text {th }}$ International Conference on Business 
Insurance Group which controls four insurers from top 10 Romanian insurance companies: Omniasig, Asirom and BCR Asigurari de Viata. The second major player is Allianz Tiriac Group, who throughout the analyzed period was one of the leaders on the insurance sector. Other important groups present in Romania are: Groupama, Generali, Uniqa, Gothaer and Eurohold. The main player on the life insurance sector from Romania is NN Asigurari de Viata (is actually the former ING Asigurari de Viata).The evolution of the number of insurers of the Romanian market and the most important changes that happened on the insurance market in the last ten years may be summarized in the figure below:

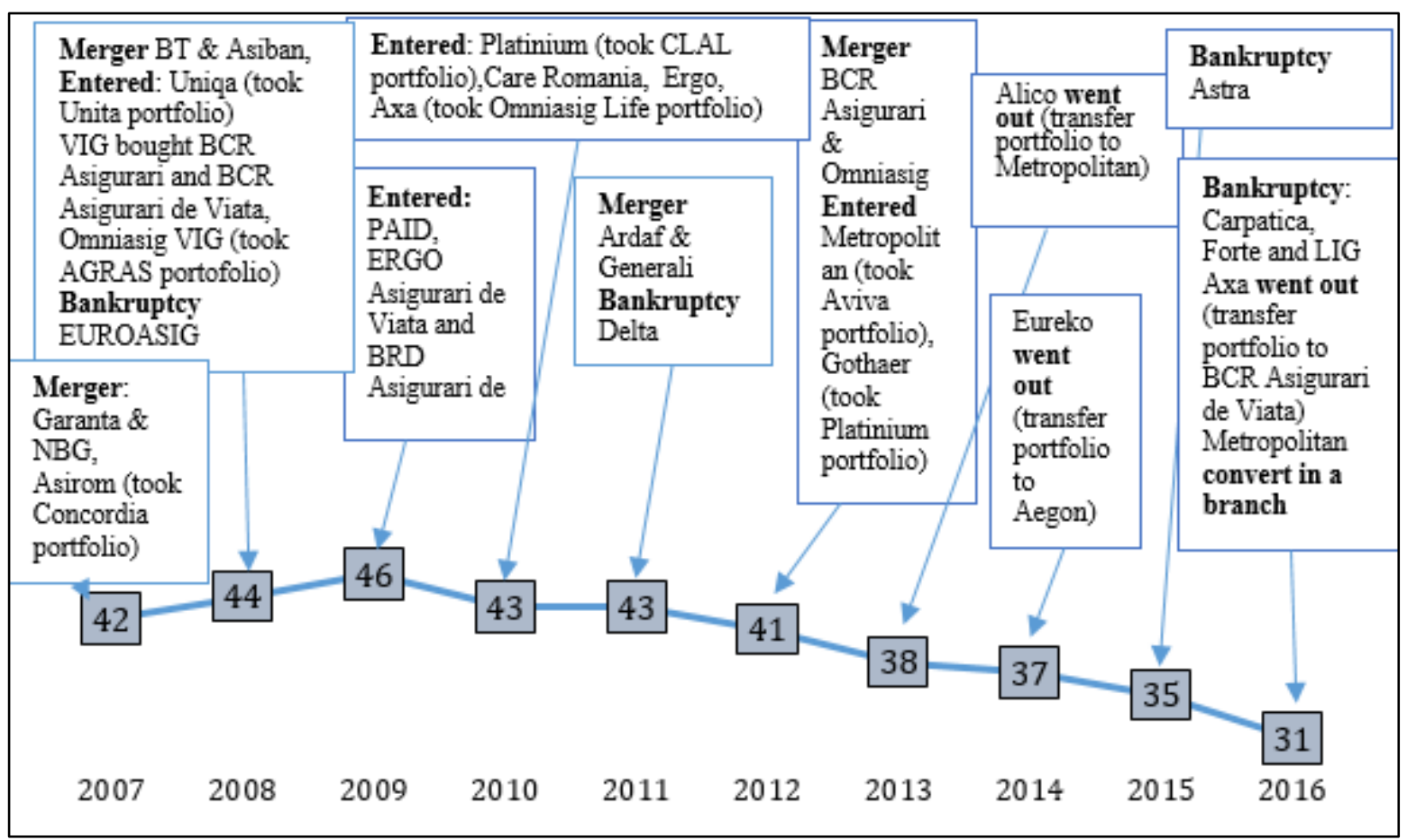

Figure 1. Evolution of insurers' number over 2007 - 2016 period

Source: Authors' own research based on the Annual reports published by Financial Supervision Authority (ASF) over 2007 - 2016 period available on www.asf.ro.

During the 2007-2016 period, the number of insurance companies has decreased from 42 insurers in 2007 year to 31 insurers in 2016 year, especially due to the mergers and acquisitions and bankruptcies.

The Central and Eastern European trend of market consolidation, materialized in four important mergers has regrouped the classifications on the Romanian insurance sector. The consolidation process was based on two main objectives: the reduction of fixed and operating expenses and increase of market share. The first important merger over the analyzed period took place in 2009 between Asiban and BT Asigurari, purchased by the French Group Groupama. In 2011, it was the merger between Ardaf and Generali. In 2012, the merger between Omniasig and BCR Asigurari was the biggest merger \& acquisition operation on the Romanian insurance industry. The latest merger on the Romanian profile market was in 2017 between BCR Asigurari de Viata VIG and AXA Life Insurance.

In the last two years, four companies went out of business on the local market: Astra Asigurari, Carpatica Asigurari, Forte Insurance and LIG Insurance. The biggest 
bankruptcy was of insurer Astra in 2015 after a year and a half of special administration. In 2014, Astra Asigurari was the third biggest insurer in Romania, with a 9.5\% market share and a volume of total gross written premiums of 173 million EUR. The second local insurance company that went bankrupt in 2016, after Astra Asigurari, was Carpatica Asigurari. In 2015, Carpatica Asigurari was the seventh largest insurance company in Romania with a market share of $6.7 \%$ and a volume of total gross written premiums of over 130 million EUR. Moreover, the Carpatica Asigurari was one of the leaders on the motor insurance segment - third party liability (MTPL). Both insurers were owned by Romanian investors. Also, in 2016, Financial Supervisory Authority, decided to start of the bankruptcy procedure for two small insurers: LIG Insurance and Forte Asigurari.

The evolution of the indicators related to concentration in the Romanian insurance market during 2007 - 2016 period may be summarized in the following figure:

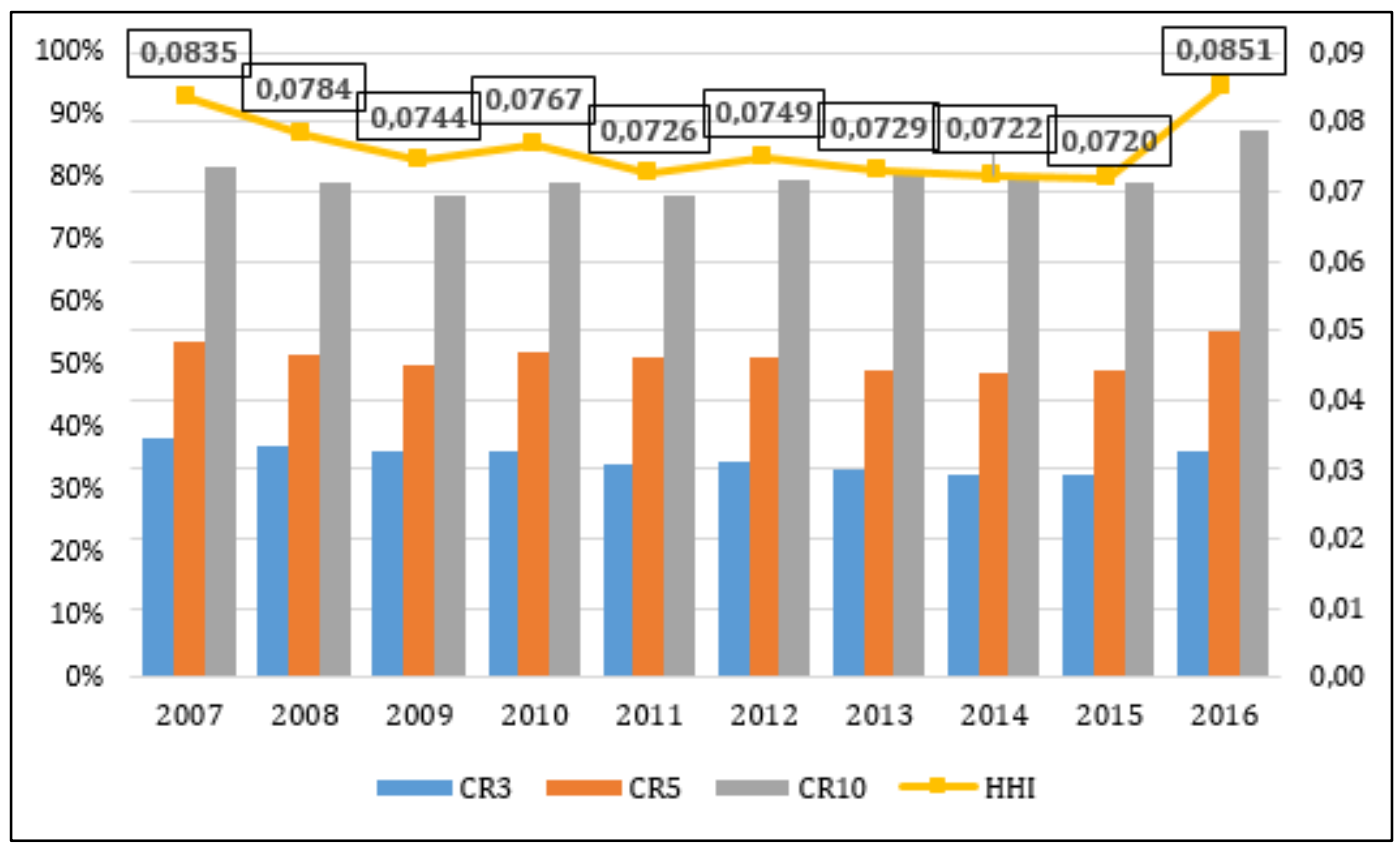

Figure 2. Evolution of the concentration indicators over 2007 - 2016 period

Source: Authors' own research based on the Annual reports published by Financial Supervision Authority (ASF) over 2007 - 2016 period available on www.asf.ro. Concentration indicators of the insurance companies presented in the figure above reveal that the Romanian insurance sector has a high level of concentration which remained constant over the ten years analyzed. The top 5 insurers have underwriting over half of the total insurance business volume. For the largest 10 insurance companies, HHI index is closely related to the development of the CR 5 and CR 10. HHI indices during the analyzed period have recorded values below 1000, indicating a low concentration degree and high competition degree.

\section{Analysis and interpretation of empirical results of Mereuţă methodology based on the Romanian market share}

In the table 1, there are presented the empirical results obtained applying the Mereuţă methodology based on the ten structural market share insurers distributions on the Romanian insurance sector during the 2007-2016 period.

DOI: 10.2478/picbe-2018-0028, pp. 311-323, ISSN 2558-9652| Proceedings of the $12^{\text {th }}$ International Conference on Business Excellence 2018 
Table 1: Empirical result of structural market shares insurers distributions

\begin{tabular}{|c|c|c|c|c|c|c|c|c|c|c|}
\hline & & & & & & & & & & \multicolumn{2}{c|}{ Matrix } \\
Year & $n$ & $p_{\max }$ & $\mu$ & $\sigma$ & $V$ & $v$ & $H H I$ & $M$ & GDL \\
\hline 2007 & 42 & $17,20 \%$ & 0,0238 & 0,0382 & 1,6029 & 0,0053 & 0,0835 & 0,3357 & 0,3385 & 1 \\
\hline 2008 & 44 & $15,49 \%$ & 0,0227 & 0,0365 & 1,6059 & 0,0061 & 0,0784 & 0,3273 & 0,2899 & 1 \\
\hline 2009 & 46 & $14,50 \%$ & 0,0217 & 0,0342 & 1,5732 & 0,0038 & 0,0744 & 0,3213 & 0,2667 & 1 \\
\hline 2010 & 43 & $13,04 \%$ & 0,0233 & 0,0357 & 1,5340 & 0,0046 & 0,0767 & 0,3173 & 0,2031 & 1 \\
\hline 2011 & 43 & $12,89 \%$ & 0,0233 & 0,0343 & 1,4730 & 0,0054 & 0,0726 & 0,3025 & 0,2106 & 1 \\
\hline 2012 & 41 & $13,70 \%$ & 0,0244 & 0,0355 & 1,4567 & 0,0051 & 0,0749 & 0,3020 & 0,2320 & 1 \\
\hline 2013 & 38 & $11,34 \%$ & 0,0263 & 0,0355 & 1,3479 & 0,0070 & 0,0729 & 0,2800 & 0,1542 & 1 \\
\hline 2014 & 37 & $12,18 \%$ & 0,0270 & 0,0354 & 1,3107 & 0,0072 & 0,0722 & 0,2721 & 0,1835 & 1 \\
\hline 2015 & 35 & $12,05 \%$ & 0,0278 & 0,0356 & 1,2801 & 0,0079 & 0,0720 & 0,2601 & 0,1781 & 1 \\
\hline 2016 & 31 & $13,08 \%$ & 0,0303 & 0,0414 & 1,3655 & 0,0063 & 0,0851 & 0,2825 & 0,1743 & 1 \\
\hline
\end{tabular}

Source: Authors' own research based on empirical results of Mereuță methodology.

Analyzing the data presented in the table above, it can be concluded that the ten structural market share insurers distributions on the Romanian insurance sector during the 2007-2016 period have satisfied all the hypothesis of Mereuţă methodology.

According to the universal concentration matrix developed by Mereuţă, the $M$ and GDL coefficients, over the analyzed period, recorded reduced values that place the Romanian insurance market in the area 1 of the competition distortion matrix. The matrix areas indicates that the Romanian insurance market had very reduced distortion of competition with a low concentration and distortion of competition by the leader of the market. The leader market share recorded a decrease from $17.2 \%$ to $13.08 \%$. The Romanian insurance market over the analyzed period had quasi-perfect competition, characterized by low entry barriers and small influence of the leader. The "nodal" insurers analysis was based on the Pareto principle for the companies covering $80 \%$ of the Romanian insurance market share.

The results for the Herfindahl indices of the insurers that combined $80 \%$ of the total market share are presented in the table below:

Table2: The "nodal" insurers analysis of the Romanian insurance market over 2007-2016 period

\begin{tabular}{|r|r|r|r|}
\hline \multicolumn{1}{|c|}{ Year } & \multicolumn{1}{|c|}{ N80 } & HHI80 & HHI80 / HHI \\
\hline 2007 & 10 & 0,0808 & $96,73 \%$ \\
\hline 2008 & 10 & 0,0759 & $96,79 \%$ \\
\hline 2009 & 11 & 0,0709 & $95,31 \%$ \\
\hline 2010 & 10 & 0,0723 & $94,26 \%$ \\
\hline 2011 & 11 & 0,0692 & $95,32 \%$ \\
\hline 2012 & 10 & 0,0711 & $94,94 \%$ \\
\hline 2013 & 10 & 0,0697 & $95,60 \%$ \\
\hline 2014 & 10 & 0,0679 & $94,01 \%$ \\
\hline 2015 & 10 & 0,0678 & $94,19 \%$ \\
\hline 2016 & 9 & 0,0812 & $95,46 \%$ \\
\hline
\end{tabular}

Source: Authors' own research based on empirical results of Mereuţă methodology. 
The number of nodal" insurers in the Romanian insurance sector during the analyzed period have been between 9 and 11 .

The table below summarizes the concentration ratios of the largest ten insurers during the 2007 - 2016 period:

Table 3: Concentration ratio of the 10 largest Romanian insurers over the 2007-2016 period: PICBE | 319

\begin{tabular}{|l|l|l|l|l|l|l|l|l|l|l|}
\hline Year & $\mathbf{2 0 0 7}$ & $\mathbf{2 0 0 8}$ & $\mathbf{2 0 0 9}$ & $\mathbf{2 0 1 0}$ & $\mathbf{2 0 1 1}$ & $\mathbf{2 0 1 2}$ & $\mathbf{2 0 1 3}$ & $\mathbf{2 0 1 4}$ & $\mathbf{2 0 1 5}$ & $\mathbf{2 0 1 6}$ \\
\hline CR 10 (\%) & 81,78 & 79,05 & 76,96 & 79,18 & 76,98 & 79,70 & 80,49 & 79,45 & 79,25 & 87,44 \\
\hline
\end{tabular}

Source: Authors' own research based on the Annual reports published by Financial Supervision Authority (ASF) over 2007 - 2016 period available on www.asf.ro.

The empirical results presented in the table above, show that the Romanian insurance market is close to the results from the perspective of Pareto principle, with a more accentuated tendency in the last year. In 2016, $87 \%$ of the total volume of gross premiums written was conducted by 10 insurance companies out of 31 that were carrying out insurance activity at December 31 ${ }^{\text {st }}, 2016$. The high value of the market share for the ten largest insurers recorded in the 2016 year is due to the bankruptcies of the insurers Astra and Carpatica, which had a significant market share and their bankruptcy caused the distribution of their market shares to other competitors.

The market insurance leader during the ten years analyzed period, in terms of total gross written premiums was Allianz Tiriac Asigurari, being surpassed in the 2010-2013 period by ASTRA Asigurari.

Analysis and interpretation of empirical results of Mereuţă methodology based on the Romanian market share according to country of the origin of capital

In the table 6, there are presented the empirical results obtained applying the Mereuţă methodology of the ten structural market share insurers distributions according to country of the origin of capital during the 2007-2016 period.

Table 4: Empirical result of structural market shares insurers distributions according to country of the origin of capital

\begin{tabular}{|r|c|c|c|c|c|c|c|c|c|r|}
\hline Year & $\mathbf{n}$ & $\mathbf{p}_{\max }$ & $\boldsymbol{\mu}$ & $\boldsymbol{\sigma}$ & $\mathbf{V}$ & $\mathbf{v}$ & HHI & $\mathbf{M}$ & $\mathbf{G D L}$ & Matrix area \\
\hline 2007 & 16 & $38,47 \%$ & 0,0625 & 0,1060 & 1,6968 & 0,0121 & 0,2312 & 0,4718 & 0,6160 & $5 \mathrm{c}$ \\
\hline 2008 & 16 & $36,70 \%$ & 0,0625 & 0,1005 & 1,6077 & 0,0133 & 0,2139 & 0,4438 & 0,6048 & $5 \mathrm{c}$ \\
\hline 2009 & 15 & $37,32 \%$ & 0,0667 & 0,0991 & 1,4861 & 0,0329 & 0,2041 & 0,4131 & 0,6599 & $5 \mathrm{c}$ \\
\hline 2010 & 13 & $33,35 \%$ & 0,0769 & 0,0940 & 1,2220 & 0,0362 & 0,1830 & 0,3378 & 0,5751 & $5 \mathrm{~d}$ \\
\hline 2011 & 13 & $33,43 \%$ & 0,0769 & 0,0932 & 1,2117 & 0,0374 & 0,1812 & 0,3340 & 0,5848 & $5 \mathrm{~d}$ \\
\hline 2012 & 13 & $31,64 \%$ & 0,0769 & 0,0904 & 1,1748 & 0,0539 & 0,1749 & 0,3203 & 0,5368 & $5 \mathrm{~d}$ \\
\hline 2013 & 13 & $27,89 \%$ & 0,0769 & 0,0838 & 1,0899 & 0,0621 & 0,1613 & 0,2886 & 0,4392 & $5 \mathrm{~d}$ \\
\hline 2014 & 13 & $25,45 \%$ & 0,0769 & 0,0801 & 1,0416 & 0,0587 & 0,1540 & 0,2705 & 0,3723 & 1 \\
\hline 2015 & 13 & $27,83 \%$ & 0,0769 & 0,0812 & 1,0558 & 0,0718 & 0,1561 & 0,2758 & 0,4543 & $5 \mathrm{~d}$ \\
\hline 2016 & 12 & $31,74 \%$ & 0,0833 & 0,0940 & 1,1283 & 0,0693 & 0,1806 & 0,3112 & 0,5177 & $5 \mathrm{~d}$ \\
\hline
\end{tabular}

Source: Authors' own research based on empirical results of Mereuţă methodology.

The ten structural market shares insurers distributions according to country of the origin of capital in the Romanian insurance sector during the 2007-2016 period have satisfied the hypothesis of Mereuţă methodology. The M and GDL coefficients, over the 
analyzed period place the competition of the Romanian insurance sector according to country of the origin of capital in followings matrix areas: the area 5c in the $2007-2009$ period and $5 \mathrm{~d}$ in the 2010-2016 period, except the year 2014.

Overall, the matrix areas suggest that the Romanian insurance sector according to country of the origin of capital, had progressed from high competition distortion areas towards low competition distortion areas. Over the analyzed period, the values of the $\mathrm{M}$ and PICBE | 320 GDL indices continuously decreased. The lower distortion that was recorded starting with the year 2010 is due to the following factors:

(1) The process of consolidation that took place in the period 2009 - 2012 by mergers and acquisitions with the reason to achieve greater market share;

(2) Promoting by some insurers inadequate strategies to increase market share (for example very low prices, especially for third party liability);

(3) The international financial crisis effects which have also been felt on the Romanian insurance sector starting with 2010 year;

(4) The bankruptcy of insurers Astra and Carpatica in the period 2015 - 2016 which had a significant contribution to the market size in the past years.

The matrix areas according to the market accessibility indicate that the Romanian insurance sector presents opportunities and risks but is still attractive for foreign investors. On average, over the analyzed period, the capital origin was in 12 to 16 countries. The number of the "nodal" countries increased from 4 in the period $2007-2009$ to 5 in the period 2010 - 2016. The figure below presents the five "nodal" countries: 


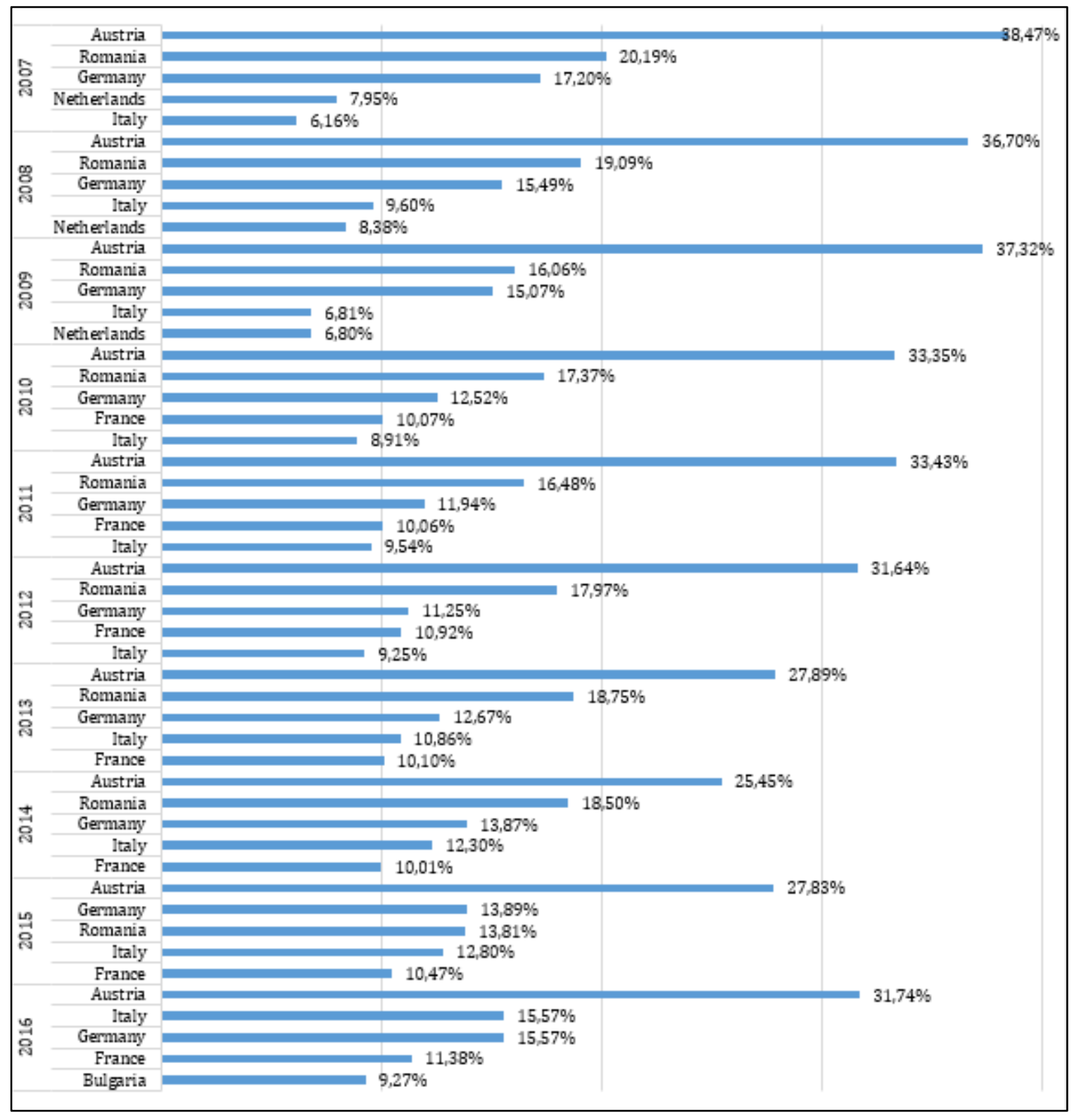

Figure 3. The market shares of the top 5 "nodal" countries during the 2007-2016 period:

Source: Authors' own research based on the Annual reports published by Financial Supervision Authority ASF) over 2007 - 2016 period available on www.asf.ro.

The first three positions that dominated the Romanian insurance sector during the analyzed period were: Austria, Romania and Germany. Year 2016 brings a significant change in the structure of the top three countries: Romania's ranking was taken by Italy. The podium of the top 5 countries according to the origin of capital is completed by France, followed by Bulgaria.

\section{Conclusions}

Analyzing the results regarding the Romanian insurance competition by applying the Mereuţă methodology, can be concluded that for new competitors the Romanian insurance 
sector presents opportunities. The competition and concentration indicators, shown a high concentration and competition on the Romanian insurance market.

The continued growth of the Romanian insurance market competition is due to the foreign capital penetration. After the bankruptcy of the companies with Romanian capital Astra and Carpatica, the Romanian market share has recorded a major decline from about $20 \%$ in 2007 to only $6.8 \%$ in 2016 . The high dependence of Romanian insurance market to the foreign capital leads to an increase in the vulnerability and the risk of contagion, as well. The Mereuţă matrix areas determined based on the Romanian market share according to country of the origin of capital, suggest that the Romanian insurance sector presents opportunities and risks but is still attractive for foreign investors.

The introduction of Solvency II directive at the beginning of year 2016, with the goal to ensure for all European insurers, the integration, globalization and the unitary functioning on the same insurance market and the recent measures taken by several Romanian insurance undertakings to strengthen their financial position, were a major step to further encourage the improvement of market competition and better policyholder protection.

The Balance Sheet Review and Balance Sheet Review Extended conducted in 2015 by Romanian Financial Supervision Authority in cooperation with European Insurance and Occupational Pensions Authority shown that a number of insurers need to take actions to improve their solvency position. Following the introduction of Solvency II that was applicable since the beginning of 2016, several insurance companies have been taking measures to strengthen their capital positions and optimize their risk profile. Capital infusion from abroad in Romanian insurers was worth 90 million euro during January September 2016, according to the data published by the National Association of Insurance and Reinsurance Companies in Romania. In the first quarter of 2017, the injection of capital continued, four insurance companies received capital infusion worth over 43.12 million EUR from foreign shareholders according to the data published by the Commerce Registry.

Taking into account that the third party liability (MTPL) is preponderant on the Romanian insurance market, the end of the "MTPL tariff cap" should improve the competition and should lead to the stabilization on the motor insurance business.

\section{References}

Badea, D. (2008). Romanian insurance market - benefits and costs after EU accession. International Conference of ASECU, Bucharest.

Badea, D., Novac L.E. (2008). Romanian Insurance Market Facing Globalization Process, Theoretical and Applied Economics, 62 - 68.

Buşu, M. (2012). An economic analysis on the degree of market concentration: Competition Indicators. Proceedings of the 6th International Management Conference

"Approaches in organizational Management", Bucharest, 529-537.

Căpraru, B., Moise, N. (2015). Insurance market's competition in Romania after 2007. Procedia Economics and Finance 20, 112 - 118.

Domide, G.S., Zelinschi, G.A., Domide, A., Horgos, G.M. (2011). Insurance market evolution in Romania in terms of global economic crisis. International conference of scientific paper AFASES, Brasov. 
Kwon, W.J., Wolfrom, L. (2016). Analytical tools for the insurance market and macroprudential surveillance. OECD Journal: Financial Market Trends, published online first. http://dx.doi.org/10.1787/fmt-2016-5jln6hnvwdzn.

Lee, C. C., Lin, C. W. (2016). Globalization, political institutions, financial liberalization, and performance of the insurance industry. North American Journal of Economics and Finance 36 (2016) 244-266.

PICBE | 323

Mereuţă, C., Căpraru, B. (2012). Romanian Banking Competition. A New Structural Approach. Working Papers of National Institute of Economic Research, http://www.studiieconomice.ro/2012/seince120722.pdf.

Njegomira, V., Marović, B. (2012). Contemporary trends in the global insurance industry. Procedia - Social and Behavioral Sciences 44, $134-142$.

Plunkett, J.W. (2006). Plunkett's Insurance Industry Almanac 2007: The Only Complete Reference To The Insurance And Risk Management Industry, Houston: Plunkett Research, Ltd.

Pope, N., Ma, Y. L. (2008). The market structure-performance relationship in the international insurance sector. Journal of Risk and Insurance, 75, 947-966

Financial Supervision Authority, Annual Reports, 2007, 2008, 2009, 2010, 2011, 2012, 2013, 2014, 2015 and 2016, available online on www.asf.ro.

National Association of Insurance and Reinsurance Companies (UNSAR), available online on http://unsar.ro/comunicate-de-presa/unsar-a-sesizat-comisia-europeana-cuprivire-la-plafonarea-tarifelor-rca.html. 